\title{
Structural and Magnetic Studies of the Fe-Co-Zr-Mo-W-B Amorphous Alloy
}

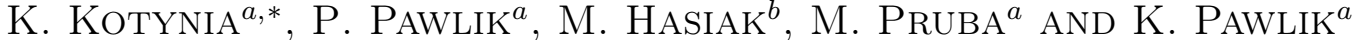 \\ ${ }^{a}$ Institute of Physics, Częstochowa University of Technology, Częstochowa, Poland \\ ${ }^{b}$ Department of Mechanics and Materials Science, Wrocław University of Science and Technology, Wrocław, Poland
}

\begin{abstract}
The paper presents a characterization of the phase structure by X-ray diffraction and isothermal magnetic entropy changes for the amorphous $\mathrm{Fe}_{58} \mathrm{Co}_{10} \mathrm{Zr}_{10} \mathrm{Mo}_{5} \mathrm{~W}_{2} \mathrm{~B}_{15}$ alloy sample in the as-quenched state. An ingot sample was obtained by arc-melting. The ribbon sample was obtained by the melt-spinning technique. The magnetic measurements at various temperatures allowed for the study of the Curie temperature $T_{\mathrm{C}}$ and magnetic entropy changes $\left|\Delta S_{M}\right|$. In order to determine the Curie temperature $T_{\mathrm{C}}$ of amorphous phase, three independent methods were used. Determination of the Curie temperature $T_{\mathrm{C}}$ for the amorphous alloys is not a trivial problem, as magnetization does not decreases rapidly around $T_{\mathrm{C}}$. Therefore it is essential issue to establish $T_{\mathrm{C}}$ using few complementary methods. X-ray diffraction analysis revealed a fully amorphous structure of the ribbon samples.
\end{abstract}

DOI: 10.12693/APhysPolA.131.1204

PACS/topics: 61.43.Dq, 75.50.Kj, 75.30.Sg, 75.30.Kz, 75.40.--s

\section{Introduction}

Magnetic refrigerators based on magnetocaloric effect (MCE) working below room temperature are currently attracting much interest. The MCE offers an energy efficient and environmental friendly alternative to the traditional refrigeration or heat pumps [1-3]. The development of Fe-based amorphous soft magnetic materials with a wide supercooled liquid region and good glass formability has become an important research topic in recent years $[4-6]$.

The MCE is significant mostly at around the phase transition temperature. The search for new magnetocaloric material for commercial applications has concentrated mainly around the tunable $T_{\mathrm{C}}$ and reasonable changes of magnetic entropy $\left(\Delta S_{M}\right)[7]$.

Iron based metallic glasses have attracted great attention of researchers, due to their good magnetic and mechanical properties, as well as the possibility of utilizing the magnetocaloric effect. There are three main factors allowing to estimate the potential of magnetocaloric materials: the magnetic entropy change $\left(\Delta S_{M}\right)$, the adiabatic temperature change $\left(\Delta T_{a d}\right)$ and the relative cooling power (RCP) [8]. An ideal magnetic refrigerant material has to possess large values of both $\Delta S_{M}$ and $\Delta T_{a d}$ as well as high RCP around room temperature at a low magnetic field [9]. The RCP is actually considered to be the most important factor for assessing the usefulness of magnetic refrigerant material $[10,11]$. The investigation of the $-\Delta S_{M}$ is one of the method which allows one to obtain information about the magnetic phase transition in these materials as well as to assess the MCE. *

\footnotetext{
* corresponding author; e-mail

kotynia.katarzyna@wip.pcz.pl
}

The $\mathrm{Fe}_{60} \mathrm{Co}_{8} \mathrm{Zr}_{10} \mathrm{Mo}_{5} \mathrm{~W}_{2} \mathrm{~B}_{15}$ alloy attracts a lot of attention, due to the wide supercooled liquid region before crystallization, a high glass-forming ability (GFA), thermal stability, strength and corrosion resistance. It reveals however low Curie temperature $[4,12,13]$. A promising iron based alloy with good GFA seems to be the $\mathrm{Fe}_{58} \mathrm{Co}_{10} \mathrm{Zr}_{10} \mathrm{Mo}_{5} \mathrm{~W}_{2} \mathrm{~B}_{15}$. By changing the $\mathrm{Fe}$ and $\mathrm{Co}$ ratio it is possible to modify $T_{\mathrm{C}}$ for this type of material to get its value around room temperature.

The aim of the present work was to determine the phase structure and magnetic properties of the rapidly solidified ribbons of the $\mathrm{Fe}_{58} \mathrm{Co}_{10} \mathrm{Zr}_{10} \mathrm{Mo}_{5} \mathrm{~W}_{2} \mathrm{~B}_{15}$ alloy and discuss the possibility of their application as the magnetic refrigerant.

\section{Experimental}

The $\mathrm{Fe}_{58} \mathrm{Co}_{10} \mathrm{Zr}_{10} \mathrm{Mo}_{5} \mathrm{~W}_{2} \mathrm{~B}_{15}$ alloy ingot was prepared by arc-melting technique of the high purity $(99.98 \%)$ constituent elements $\mathrm{Fe}, \mathrm{Co}, \mathrm{Zr}, \mathrm{Mo}, \mathrm{W}$ with the addition of pre-alloyed $\mathrm{Fe}-\mathrm{B}$. Ingot was re-melted at least seven times to guarantee the homogeneity of the alloy.

The ribbon was prepared by the melt-spinning technique at the surface velocity of the copper roller of $40 \mathrm{~m} / \mathrm{s}$. Both the arc-melting and melt-spinning were performed under Ar atmosphere to avoid oxidation.

The phase structure was investigated by X-ray diffraction (XRD) using Bruker D8 Advance with $\mathrm{Cu} K_{\alpha}$ radiation and the LynxEye dimensional compound strip detector. The data were recorded using the step-scanning method in $2 \Theta$ range from 25 to 100 degrees.

Temperature dependences of magnetization were measured by VersaLab (Quantum Design) system. Magnetic measurements $\mathrm{M}(\mathrm{H})$ in the temperature range 225-325 $\mathrm{K}$ were performed and the magnetocaloric effect (MCE) was estimated by calculation of the temperature and field dependences of magnetic entropy change $-\Delta S_{M}$. The magnetic entropy change $-\Delta S_{M}$ was calculated using the Maxwell thermodynamic formula [14]: 


$$
\Delta S_{M}(T H)=\int_{0}^{H}\left(\frac{\partial M(T, H)}{\partial T}\right)_{H} \mathrm{~d} H,
$$

where $T$ - temperature, $M(T, H)-$ magnetization, $H$ - external magnetic field.

From thermomagnetic curves the Curie temperature of the $\mathrm{Fe}_{58} \mathrm{Co}_{10} \mathrm{Zr}_{10} \mathrm{Mo}_{5} \mathrm{~W}_{2} \mathrm{~B}_{15}$ alloy was determined. Furthermore, the isothermal Arrott plots were constructed and the magnetic entropy changes were calculated $[15,16]$.

\section{Results and discussion}

In Fig. 1 the XRD pattern of the as-cast $\mathrm{Fe}_{58} \mathrm{Co}_{10} \mathrm{Zr}_{10} \mathrm{Mo}_{5} \mathrm{~B}_{15}$ ribbon is presented. The ribbon exhibits a typical broad diffraction maximum characteristic for the amorphous structure without any crystalline reflexes, suggesting that the alloy can be melt-spun into the fully amorphous ribbon with a thickness of about $20 \mu \mathrm{m}$.

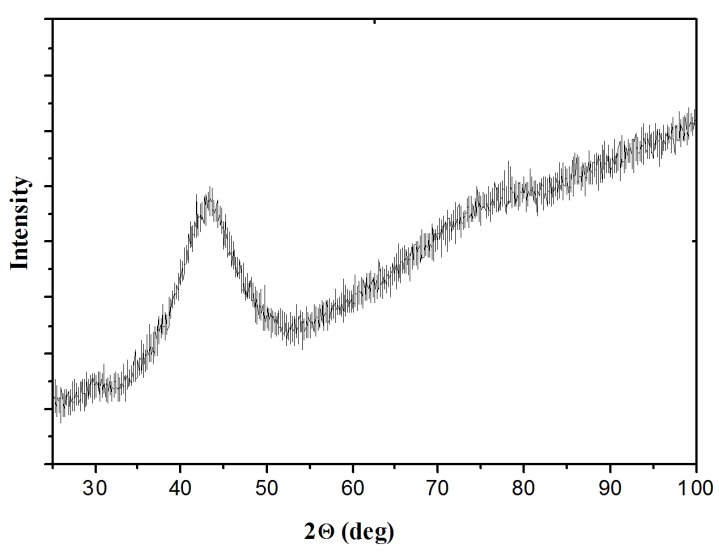

Fig. 1. The XRD pattern measured for the $\mathrm{Fe}_{58} \mathrm{Co}_{10} \mathrm{Zr}_{10} \mathrm{Mo}_{5} \mathrm{~W}_{2} \mathrm{~B}_{15}$ sample in the as-cast state.

The temperature dependences in FC mode magnetization measured for the $\mathrm{Fe}_{58} \mathrm{Co}_{10} \mathrm{Zr}_{10} \mathrm{Mo}_{5} \mathrm{~W}_{2} \mathrm{~B}_{15}$ alloy were recorded at $2.5,5$, and $15 \mathrm{mT}$ and the corresponding $\mathrm{d} M / \mathrm{d} T$ curves were presented in Fig. 2. With increasing temperature, a drop of magnetization is observed below $T_{\mathrm{C}}$. The Curie temperature $T_{\mathrm{C}}$ is determined from the condition $\mathrm{d} M / \mathrm{d} T=$ minimum and its value $T_{\mathrm{C}}$ reaches $263 \mathrm{~K}$.

The Curie temperature $T_{\mathrm{C}}$ can be determined using the equation [17]:

$$
M(T)=M(0)\left(1-\frac{T}{T_{\mathrm{C}}}\right)^{\beta},
$$

where $M(0)$ is the saturation magnetization at $0 \mathrm{~K}$ and $\beta$ is constant of 0.36 . The Curie temperature was determined from $M^{1 / \beta}$ vs. $T$ curves measured at various external magnetic fields (Fig. 3 ) and extrapolated to zero field (inset in Fig. 3). The values of $T_{\mathrm{C}}$ determined using this method reaches $263 \mathrm{~K}$.

From the magnetization isotherms presented in Fig. 4, the Arrott plots were constructed in order to determine $T_{\mathrm{C}}$ and confirm the order of phase transition (Fig. 5). For the linear parts of $M^{2}\left(\mu_{0} H / M\right)$ curves the relation

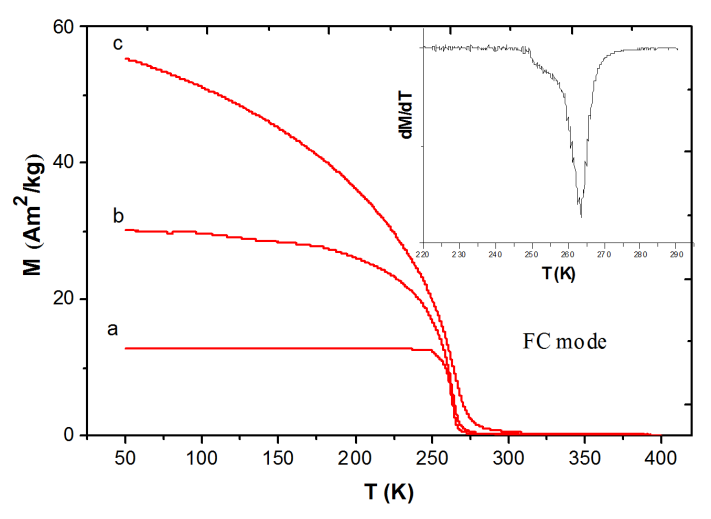

Fig. 2. The temperature dependence of the field cooled (FC) magnetization for the $\mathrm{Fe}_{58} \mathrm{Co}_{10} \mathrm{Zr}_{10} \mathrm{Mo}_{5} \mathrm{~W}_{2} \mathrm{~B}_{15}$ alloy ribbon at external magnetic fields: (a) $2.5 \mathrm{mT}$, (b) $5 \mathrm{mT}$, and (c) $15 \mathrm{mT}$. The inset shows a derivative curve of $\mathrm{d} M / \mathrm{d} T$.

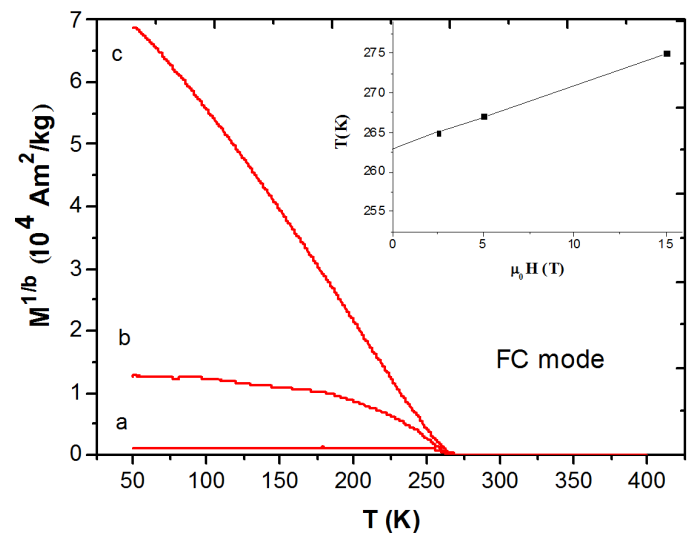

Fig. 3. The modified the curve of $M^{1 / \beta}(T)$ with a critical parameter $(\beta=0.36)$ for magnetization for the $\mathrm{Fe}_{58} \mathrm{Co}_{10} \mathrm{Zr}_{10} \mathrm{Mo}_{5} \mathrm{~W}_{2} \mathrm{~B}_{15}$ alloy ribbon at external magnetic fields: (a) $2.5 \mathrm{mT}$, (b) $5 \mathrm{mT}$, and (c) $15 \mathrm{mT}$.

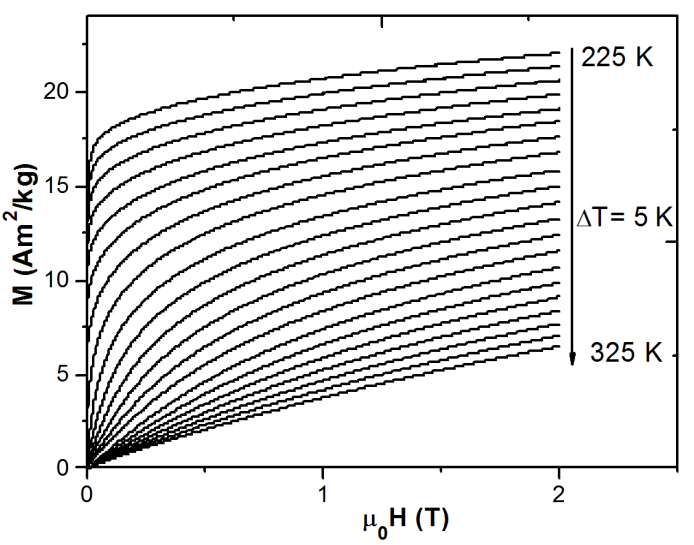

Fig. 4. The magnetization isotherms for the $\mathrm{Fe}_{58} \mathrm{Co}_{10} \mathrm{Zr}_{10} \mathrm{Mo}_{5} \mathrm{~W}_{2} \mathrm{~B}_{15}$ alloy ribbon from 225 to $325 \mathrm{~K}$. 
$M_{s p}^{2}$ vs. $T$ (where $M_{s p}$ - spontaneous magnetization) was drawn and $T_{\mathrm{C}}$ was determined as a interception of this line with $T$ axis (inset in Fig. 5). The $T_{\mathrm{C}}$ value obtained using this method reached $270 \mathrm{~K}$. The character of the Arrott plots is typical for the second order phase transition in the amorphous sample [16].

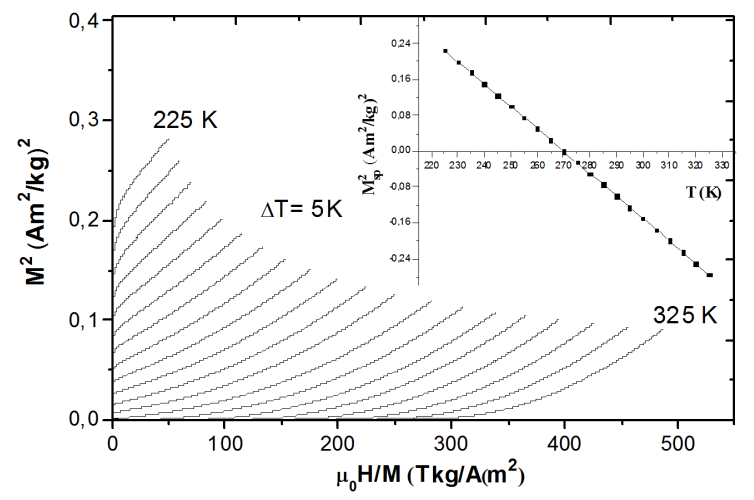

Fig. 5. Arrott plots, i.e. $M^{2}$ versus $\mu_{0} H / M$ for $\mathrm{Fe}_{58} \mathrm{Co}_{10} \mathrm{Zr}_{10} \mathrm{Mo}_{5} \mathrm{~W}_{2} \mathrm{~B}_{15}$ alloy. Inset: linear fit of $M_{s p}^{2}$ versus $T$ to determine the Curie point.

Furthermore, the temperature changes of $-\Delta S_{M}$ were also determined from magnetization isotherms (Fig. 6). The maximum value of $-\Delta S_{M}$ reached $0.44 \mathrm{~J} \mathrm{~kg}^{-1} \mathrm{~K}^{-1}$ for the maximum change of the external magnetic field up $2 \mathrm{~T}$.

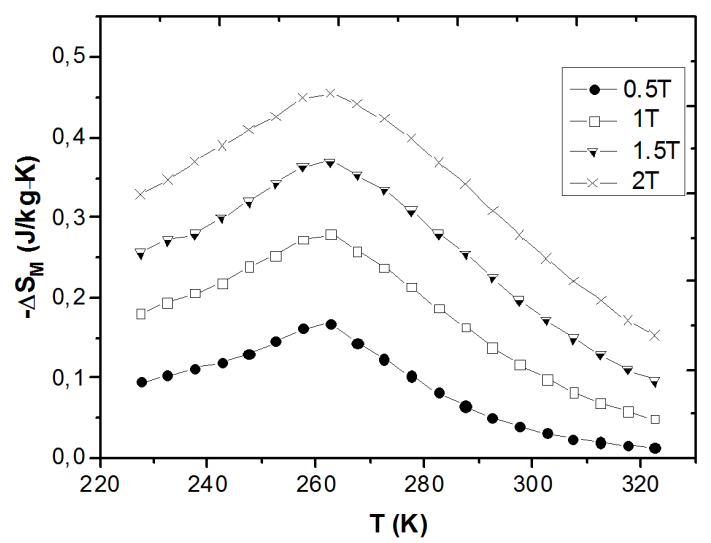

Fig. 6. Magnetic entropy change $-\Delta S_{M}$ around the Curie temperature $T_{\mathrm{C}}$ measured for $\mathrm{Fe}_{58} \mathrm{Co}_{10} \mathrm{Zr}_{10} \mathrm{Mo}_{5} \mathrm{~W}_{2} \mathrm{~B}_{15}$ alloy at magnetic field changes from 2 (top) to $0.5 \mathrm{~T}$ (bottom).

\section{Conclusions}

In the present studies the magnetic and structural properties in $\mathrm{Fe}_{58} \mathrm{Co}_{10} \mathrm{Zr}_{10} \mathrm{Mo}_{5} \mathrm{~W}_{2} \mathrm{~B}_{15}$ alloy ribbon have been investigated. Characteristic of the XRD studies confirmed the amorphous structure of melt-spun ribbons.

The Curie temperature of the amorphous ribbon was determined using three techniques. In the first one, $T_{\mathrm{C}}$ was obtained from the measurements of temperature dependences of the FC magnetization. Using this method
$T_{\mathrm{C}}$ reached $263 \mathrm{~K}$. In the second approach, the $T_{\mathrm{C}}$ was obtained from a derivative curve of $\mathrm{d} M / \mathrm{d} T$ and values of $T_{\mathrm{C}}$ reached $263 \mathrm{~K}$. In the third approach, the Arrott plots were derived from the initial magnetization curves measured at various temperatures. The determined value of $T_{\mathrm{C}}$ reached $270 \mathrm{~K}$.

The maximum magnetic entropy change $\Delta S_{M \max }=$ $0.44 \mathrm{~J} \mathrm{~kg}^{-1} \mathrm{~K}^{-1}$ at the change of external magnetic field at $2 \mathrm{~T}$ is not very high, but the range of temperatures at which $-\Delta S_{M}$ maintain a significant level seems to be promising for application. Therefore, further studies focused on doping the base alloy with Gd are in progress. Furthermore an appropriate admixture of the base alloy will result in the shift of $T_{\mathrm{C}}$ to the higher temperatures. The tunable $T_{\mathrm{C}}$ around room temperature makes this alloy potentially useful for the development of magnetocaloric regenerators.

\section{References}

[1] V.K. Pecharsky, K.A. Jr. Gschneidner, Phys. Rev. Lett. 78, 4494 (1997).

[2] J.Y. Law, V. Franco, R.V. Ramanujan, J. Appl. Phys. 111, 113919 (2012).

[3] K.A. Gschneidner, V.K. Pecharsky, Annu. Rev. Mater. Sci. 30, 387 (2000).

[4] A. Inoue, Acta Mater. 48, 279 (2000).

[5] J.M. Borrego, C.F. Conde, A. Conde, S. Roth, H. Grahl, A. Ostwald, J. Eckert, J. Appl. Phys. 92, 6607 (2002).

[6] W.M. Wang, W.X. Zhang, A. Gebert, S. Roth, C. Mickel, L. Schultz, Metall. Mater. Trans. A $\mathbf{4 0}$, 511 (2009).

[7] P. Gębara, P. Pawlik, B. Michalski, J.J. Wysłocki, K. Kotynia, Acta Phys. Pol. A 128, 87 (2015).

[8] V. Chaudhary, D.V. Mahesvar Repaka, A. Chaturvedi, I. Sridhar, R.V. Ramanujan, J. Appl. Phys. 116, 163918 (2014).

[9] P. Shamba, R. Zeng, J.L. Wang, S.J. Campbell, S.X. Dou, J. Magn. Magn. Mater. 331, 102 (2013).

[10] M.H. Phan, S.C. Yu, J. Magn. Magn. Mater. 308 , 325 (2007).

[11] W.J. Feng, J. Du, B. Li, W.J. Hu, Z.D. Zhang, X.H. Li, Y.F. Deng, J. Phys. D Appl. Phys. 42, 125003 (2009).

[12] B. Yang, C.T. Liu, T.G. Nieh, M.L. Morrison, P.K. Liaw, R.A. Buchanan, J. Mater. Res. 21, 915 (2006).

[13] P. Pawlik, H.A. Davies, J. Non-Cryst. Solids 329, 17 (2003).

[14] V.K. Pecharsky, K.A. Gschneidner, J. Appl. Phys. 86, 565 (1999).

[15] J. Świerczek, J. Magn. Magn. Mater. 322, 2696 (2010).

[16] M.D. Regulacio, K. Bussmann, B. Lewis, S.L. Stoll, J. Am. Chem. Soc. 128, 11173 (2006).

[17] L. Banas, Z. Brzeźniak, M. Neklyudov, A. Prohl, Stochastic Ferromagnetism, de Gruyter, Berlin 2014, p. 198. 